\title{
PEMERIKSAAN JAMUR Candida sp PADA RONGGA MULUT LANSIA DI PANTI SOSIAL TRESNA WERDHA BUDI MULIA 1 CIPAYUNG JAKARTA TIMUR
}

\author{
Lenggo Geni ${ }^{1)}$, Rawina Winita ${ }^{2)}$, Anita Astuti Istiqomah' ${ }^{1)}$. \\ ${ }^{1}$ Program Studi Analis Kesehatan, Fakultas Kesehatan, Universitas Mohammad Husni Thamrin \\ ${ }^{2}$ Parasitologi FK UI \\ Correspondence author:Lenggo Geni, lenggogeni19@gmail.com, Jakarta, Indonesia
}

\begin{abstract}
ABSTRAK
Candida adalah anggota flora normal terutama saluran pencernaan, juga selaput mukosa saluran pernafasan, vagina, uretra, kulit dan dibawah jari-jari kuku tangan dan kaki. Di tempat-tempat ini ragi dapat menjadi dominan dan menyebabkan keadaan-keadaan patologik ketika daya tahan tubuh menurun baik secara lokal maupun sistemik. Penelitian ini bertujuan untuk mengetahui persentase keberadaan jamur Candida $s p$ pada rongga mulut lansia .

Penelitian ini menggunakan metode Biakan yang ditanam pada media SDA dan dibaca secara Makroskopis, dan Mikroskopis yang dilakukan pada 62 sampel Swab rongga mulut lansia di Panti Sosial Tresna Werdha Budi Mulia 1 Cipayung Jakarta Timur. Analisis data yang digunakan adalah deskriptif. Dari hasil pemeriksaan makroskopis dan mikroskopis yang hasilnya didapat berdasarkan persentase keberadaan jamur Candida $s p$ yang tumbuh pada media SDA+.Hasil penelitian dari 62 sampel didapatkan 34 (54,9\%) sampel positif Candida sp dan $28(45,1 \%)$ sampel negatif Candida $s p$ dalam pemeriksaan metode biakan SDA. Peningkatan kepadatan koloni terdapat pada hasil positif satu $(+)$ yaitu sebanyak $24(70,59 \%)$ sampel. Jamur Candida $s p$ tumbuh paling banyak pada sampel dengan frekuensi menyikat gigi $>1$ x yaitu sebanyak $24(70,59 \%)$ sampel serta pada sampel dengan keluhan adanya sariawan secara keseluruhan didapatkan hasil positif Candida sp sebanyak $6(17,65 \%)$ sampel, dan pada perilaku menyikat gigi yang menggunakan pasta gigi sebanyak $31(91,18 \%)$ sampel. Dapat disimpulkan peningakatan Jumlah Candida $s p$ karena jamur Candida $s p$ adalah flora normal yang ada pada rongga mulut dan akan meningkat dalam kondisi kelainan tertentu.
\end{abstract}

Kata Kunci $\quad$ : $\quad$ Candida $s p$, Lansia

\begin{abstract}
Candida is a member of the normal flora, especially the digestive tract, as well as the mucous membranes of the respiratory tract, vagina, urethra, skin and under the fingernails and toes. In these sites the yeast can become dominant and cause pathological conditions when the immune system decreases both locally and systemically. This study aims to determine the percentage of the presence of the fungus Candida sp in the oral cavity of the elderly.

This study used the culture method grown on SDA media and read Macroscopically, and Microscopically which was carried out on 62 samples of oral cavity swabs at the Tresna Werdha Budi Mulia 1 Social Institution, Cipayung, East Jakarta. The data analysis used is descriptive. From the results of macroscopic and microscopic examinations, the results were obtained based on the percentage of the presence of Candida sp. Growing on SDA + media.

The results of the study of 62 samples obtained 34 (54.9\%) positive samples for Candida sp and $28(45.1 \%)$ negative samples for Candida sp. In the SDA culture method examination. An increase in colony density was found in positive one (+) results, namely $24(70.59 \%)$ samples. Candida sp. Fungi grew the most in samples with a frequency of brushing $>1 \mathrm{x}$ which was $24(70.59 \%)$ samples and in samples with complaints of thrush as a whole, $6(17.65 \%)$ positive results of Candida sp. The behavior of brushing teeth using toothpaste was $31(91.18 \%)$ samples. It can be concluded that the increase in the number of Candida sp because the fungus Candida sp is a normal flora that exists in the oral cavity and will increase in certain abnormal conditions.
\end{abstract}

Keywords: Candida sp, Elderly

Open Journal System (OJS): journal.thamrin.ac.id

http://journal.thamrin.ac.id/index.php/anakes/issue/view/36 


\section{PENDAHULUAN}

Candida adalah anggota flora normal terutama saluran pencernaan, juga selaput mukosa saluran pernafasan, vagina, uretra, kulit dan dibawah jari-jari kuku tangan dan kaki. Di tempat-tempat ini ragi dapat menjadi dominan dan menyebabkan keadaan-keadaan patologik ketika daya tahan tubuh menurun baik secara lokal maupun sistemik Mikroorganisme eukariotik bersifat dimorfik, yeast (sel ragi bertunas), pseudohifa, atau hifa sejati, berbentuk oval dengan diameter 3-6 $\mu \mathrm{m}$ dan bereproduksi melalui tunas (Martyanti, 2012).

Flora normal yang terdapat pada membran mukosa, saluran pencernaan, vagina, uretra, kulit, dan kuku (Fiari dkk, 2012). Salah satu infeksi yang disebabkan oleh Candida sp adalah kandidiasis dan salah satu contohnya adalah kandidiasis mulut (Usman, 2013).

Faktor yang mempermudah terjadinya kandidiasis di rongga mulut yaitu faktor sistemik dan faktor lokal. Faktor sistemik meliputi fisiologis (umur tua, kehamilan), penurunan sistem imun, kelainan endokrin, defisiensi. Sedangkan faktor lokal meliputi pemakaian gigi tiruan, perubahan epitel, sekresi saliva menurun, pH saliva, perubahan flora rongga mulut, karbohidrat meninggi. (Hamid dalam Asti, 2015) Penelitian Departement of Microbiology, Lead City University, Nigeria pada tahun 2012 yang dilakukan pada 200 orang pengunjung Association for Reproductive Family and Health (AFRH) menyatakan bahwa infeksi Candida sp. merupakan infeksi tertinggi dengan persentase 27\% (Fiari dkk, 2012).

Lanjut usia menurut UU RI no 13 tahun1998 adalah mereka yang telah memasuki usia 60 tahun ke atas. Apapun istilah yang dikenakan pada individu yang telah memasuki usia 60 ke atas tersebut tidak lebih penting dari realitas yang dihadapi oleh kebanyakan individu usia ini. (Indriana, 2008)

Dalam kehidupan sehari-hari kebersihan merupakan hal yang sangat penting dan harus diperhatikan karena kebersihan akan mempengaruhi kesehatan, kenyamanan, keamanan, dan kesejahteraan. Praktik hygiene seseorang dipengaruhi oleh faktor pribadi, sosial, dan budaya. Jika seseorang sakit biasanya masalah kebersihan kurang diperhatikan terutama pada lansia. Hal ini terjadi karena lansia menganggap 
masalah kebersihan adalah masalah sepele, padahal jika hal tersebut dibiarkan dapat mempengaruhi status kesehatan. (Isro'in, 2012)

Penelitian mengenai jamur Candida yang dilakukan oleh Zephyra Jayanti mahasiswa jurusan D III Analis Kesehatan tahun 2017 jamur Candida albicans banyak ditemukan pada lansia pengguna gigi tiruan yang lebih dari 2 tahun dan lebih banyak ditemukan pada lansia yang frekuensi menyikat giginya 1x sehari serta memiliki keluhan sariawan. (jayanti, 2017)

Panti jompo merupakan sebuah rumah atau tempat penampungan untuk manusia lanjut usia (manula). Lanjut usia adalah periode dimana organisme telah mencapai kematangan dalam ukuran, fungsi dan telah menunjukan perubahan sejalan dengan waktu. Sehingga lansia sangat rentan terhadap penyakit serta pada usia ini sebagian lansia kurang menjaga kesehatan maupun perawatan pada tubuh di Panti Sosial Tresna Werdha Budi Mulia 1 Cipayung Jakarta Timur.

Berdasarkan latar belakang diatas maka peneliti ingin melakukan penelitian tentang pemeriksaan jamur Candida sp pada rongga mulut berdasarkan Oral Hygiene pada lansia di Panti Sosial Tresna Werdha Budi Mulia I Jakarta Timur.

\section{METODE}

Tempat pengambilan sampel dilakukan di Panti Sosial Tresna Werdha Budi Mulia 1 Cipayung Jakarta Timur pada tanggal 6 sampai dengan 7 agustus 2019. Penelitian ini dilakukan di laboratorium Mikrobiologi jurusan Analis Kesehatan MH. Thamrin mulai dari tanggal 14 sampai dengan 16 agustus 2019. Populasi dari penelitian ini adalah lansia di Panti Sosial Tresna werdha Budi Mulia 1 Cipayung Jakarta Timur. Sampel pada penelitian adalah lansia di Panti Sosial Tresna werdha Budi Mulia 1 Cipayung Jakarta Timur yang mengalami batuk dan tidak batuk yang diperiksa jamur pada Rongga Mulut berjumlah 63 orang namun pada saat pengambilan sampel hanya didapatkan 50 sampel Swab rongga mulut dari jumlah lansia yang keseluruhan populasinya adalah 210 orang yang tinggal di Panti Sosial 
Tresna werdha Budi Mulia 1 Cipayung Jakarta Tmur. sampel yang didapat dilakukan pemeriksaan biakan pada media sda

\section{HASIL \& PEMBAHASAN}

Hasil pemeriksaan dari 62 sampel swab rongga mulut lansia di Panti Sosial Tresna Werdha Budi Mulia 1 Cipayung Jakarta Timur, Dari 62 sampel yang tumbuh Candida sp dapat dilihat pada tabel 1 :

\section{Tabel 1}

\section{Hasil Pemeriksaan Candida sp Pada Rongga Mulut Lansia Di Panti Sosial Tersna Werdha Budi Mulia 1 Cipayung Jakarta Timur}

\begin{tabular}{lll}
\hline Hasil Biakan SDA & Jumlah & $\%$ \\
\hline \multicolumn{1}{c}{ Positif } & 34 & $54,9 \%$ \\
Negatif & 28 & $45,1 \%$ \\
\hline Jumlah & 62 & $100 \%$ \\
\hline
\end{tabular}

Sumber : Data Primer, Agustus 2019

Pada biakan media SDA (Saboraud Dextrose Agar) didapatkan 34 sampel (54,9\%) tumbuh koloni jamur Candida $s p$ yang mempunyai koloni lunak dengan permukaan halus, cembung, licin, berwarna putih. Dan sampel negatif sebanyak 28 sampel (45,1\%).

Pada biakan SDA+ yang sudah tumbuh koloni Candida sp kemudian dilakukan penghitungan jumlah koloni untuk melihat kepadatan koloni pada tabel 2 :

Tabel 2

Persentase Kepadatan Koloni Candida sp Pada 34 Biakan Swab Rongga Mulut Lansia di Panti Sosial Tresna Werdha Budi Mulia 1 Cipayung Jakarta Timur Berdasarkan Kepadatan Koloni

\begin{tabular}{ccc}
\hline Kepadatan Koloni & Jumlah & $\%$ \\
\hline$+\quad(1-50$ koloni $)$ & 24 & $70,59 \%$ \\
$++(50-100$ koloni $)$ & 4 & $11,76 \%$ \\
$+++(>100$ koloni $)$ & 6 & $17,65 \%$ \\
\hline Jumlah & 34 & $100 \%$ \\
\hline
\end{tabular}

sumber : Data Primer, Agustus 2019 
Pada tabel 2 dapat diketahui distribusi kepadatan koloni pada 34 sampel biakan Candida sp sebanyak 24 sampel (70,59\%) dengan kepadatan berkisar antara 1-50 koloni (+), sebanyak 4 sampel $(11,76 \%)$ dengan kepadatan berkisar 50-100 koloni (++) dan 6 sampel (17,65\%) dengan kepadatan $>100$. Adapun sampel yang negatif atau tidak tumbuh sebanyak 28 sampel dari 62 sampel yang ada.

Pertumbuhan Candida sp sangat dipengaruhi oleh perilaku kebersihan mulut. Keberadaan jamur Candida $s p$ pada rongga mulut lansia berdasarkan tingkat oral hygiene dalam perilaku menyikat gigi dapat dilihat pada tabel 3 di bawah ini :

Tabel 3

Keberadaan jamur Candida sp pada Ronga Mulut Lansia Berdasarkan Tingkat Kebersihan Mulut Dalam Perilaku Menyikat Gigi

\begin{tabular}{ccc}
\hline Perilaku Sikat Gigi & $\begin{array}{c}\text { Candida sp } \\
(+)\end{array}$ & $\%$ \\
\hline 1x sehari & 7 & $20,59 \%$ \\
>1x sehari & 24 & $70,59 \%$ \\
Tidak Sikat Gigi & 3 & $8,82 \%$ \\
\hline Jumlah & 34 & $100 \%$ \\
\hline
\end{tabular}

Pada tabel 3 tampak bahwa perilaku menyikat gigi 1x sehari didapat hasil positif Candida sp sebanyak 7 sampel (20,59\%), sedangkan dengan perilaku menyikat gigi $>1 \mathrm{x}$ sehari didapat hasil sebanyak 24 sampel (70,59\%) dan perilaku tidak menyikat gigi didapat hasil sebanyak 3 sampel $(8,82 \%)$.

Keberadaan jamur Candida yang berlebih pada rongga mulut terkadang juga dapat menimbulkan suatu keluhan. Keluhan yang muncul dapat berupa sariawan ataupun gangguan pada rongga mulut lainya. Keberadaan jamur Candida pada rongga mulut lansia berdasarkan keluhan yang timbul akibat adanya sariawan dapat dilihat pada tabel 4 di bawah ini:

Tabel 4 Keberadaan jamur Candida sp Pada Rongga Mulut Lansia Berdasarkan Adanya keluhan

\begin{tabular}{lll}
\hline Keluhan & $\begin{array}{l}\text { Candida sp } \\
(+)\end{array}$ & $\%$ \\
\hline Sariawan & 6 & $17,65 \%$ \\
Tidak ada & 28 & $82,35 \%$ \\
\hline Jumlah & 34 & $100 \%$ \\
\hline
\end{tabular}

Sumber : Data Primer, Agustus 2019 
Pada tabel 3 tampak bahwa hasil positif candida sp yang mengalami keluhan sariawan sebanyak 6 sampel $(17,65 \%)$ dan tidak mengalami keluhan sariawan sebanyak 28 sampel $(82,35 \%)$.

Keberadaan Candida pada rongga mulut juga dapat meningkat apabila menyikat gigi tanpa menggunakan pasta gigi karna salah satu penunjang kebersihan rongga mulut dan gigi adalah dengan secara rutin menyikat gigi menggunakan pasta gigi. Tanpa menggunakan pasta gigi maka sisa-siza zat makan serta sisa-sisa kotoran yang menempel pada rongga mulut akan sulit dibersihkan. Perilaku menyikat gigi dengan penggunaan pasta gigi dapat dilihat pada tabel 5:

Tabel 5

Keberadaan jamur Candida sp Pada rongga Mulut Lansia Berdasarkan Penggunaan Pasta gigi

\begin{tabular}{ccc}
\hline Pemakaian & $\begin{array}{c}\text { Candida sp } \\
(+)\end{array}$ & $\%$ \\
Pasta Gigi & 31 & $91,18 \%$ \\
Ya & 3 & $8,82 \%$ \\
Tidak & 34 & $100 \%$ \\
\hline Jumlah &
\end{tabular}

Sumber : Data Primer, Agustus 2019

Pada tabel 5 pada perilaku menyikat gigi menggunakan pasta gigi positif Candida sp sebanyak 31 sampel (91,18\%), sedangkan 3 sampel (8,82\%) tidak menggunakan pasta gigi.

Dari hasil penelitian terhadap 62 sampel swab rongga mulut lansia di Panti Sosial Tresna Werdha Budi Mulia 1 Cipayung Jakarta Timur. Pada tabel 1 tampak kepadatan koloni Candida sp dipermukaan medium SDA (Saboraud Dextrose Agar) yang menunjukan hasil positif sebanyak 34 sampel (54,9\%), dan didapatkan hasil negatif sebanyak 28 sampel $(45,1 \%)$. Pada penelitian yang dilakukan oleh Zephyra Jayanti mahasiswa D III Analis kesehatan tahun 2017 didapatkan hasil pertumbuhan Candida meningkat karna lansia pengguna gigi tiruan yang pemakaianya lebih dari 2 tahun sebanyak (71,4\%). (Jayanti,2017) Hal ini menunjukan bahwa jamur Candida sp banyak ditemukan pada rongga mulut lansia, bila jumlahnya berlebihan maka jamur ini dapat menimbulkan infeksi. (Sheina, 2002) 
Pada tabel 2 menunjukkan kepadatan koloni Candida sp, koloni yang diamati adalah koloni yang diduga merupakan jamur Candida sp dengan ciri koloni bulat dengan permukaan medium halus, licin, berwarna putih kekuningan dan berbau khas seperti ragi. Terlihat bahwa jumlah tertinggi ditemukan pada koloni positif satu $(+)$ yaitu sebanyak 24 sampel (70,59\%), sedangkan positif dua $(++)$ didapat hasil sebanyak 4 sampel $(11,76 \%)$ dan positif tiga $(+++)$ didapat hasil sebanyak 6 sampel $(17,65 \%)$. Peningkatan jumlah kepadatan koloni Candida sp pada positif satu $(+)$ hal ini dikarenakan Candida $s p$ merupakan flora normal dalam mulut orang sehat tanpa keluhan. Namun jumlahnya dapat meningkat bila kebersihan mulut tidak dijaga. (Surinder, 2016)

Pada tabel 3 dapat dilihat bahwa perilaku menyikat gigi 1x sehari didapatkan hasil 7 sampel (20,59\%), sedangkan perilaku menyikat gigi $>1 \mathrm{x}$ sebesar 24 sampel $(70,59 \%)$ dan perilaku tidak menyikat gigi didapatkan hasil sebesar 3 sampel (8,82\%). Pada perilaku menyikat gigi $>1 \mathrm{x}$ sehari didapatkan hasil lebih tinggi karna walaupun sudah melakukan kebersihan mulut seperti menyikat gigi tetapi dapat observasi dari beberapa faktor yaitu keadaan mulut yang kotor, cara menyikat gigi yang kurang tepat, dan terdapat banyaknya kotoran di selah-selah gigi dan sekitar rongga mulut serta karna pengambilan sampel yang kurang tepat dan sebaiknya pengambilan sampel dilakukan dengan air kumuran secara langsung yang didapatkan dari lansia. Hal ini juga dapat terjadi dikarenakan menggosok gigi secara tidak teratur yang dapat mengakibatkan terjadinya peningkatan jumlah Candida pada rongga mulut yang disebabkan oleh penumpukan sisa zat makanan, hal ini merupakan faktor predisposisi meningkatnya keberadaan Candida. Perilaku dalam membersihkan gigi dengan cara yang tidak benar tidak ada hubunganya dengan pertumbuhan Candida sp. Walaupun didapatkan hasil yang tinggi maka Candida sp tetap flora normal pada rongga mulut. (Zulfikar, 2013)

Pada tabel 4 tampak bahwa keberadaan Candida $s p$ sebanyak 6 sampel (17,65\%) pada lansia yang mengalami keluhan sariawan, sedangkan keberadaan Candida $s p$ yang tidak memiliki keluhan sebanyak 28 sampel (82,35\%). Hal ini disebabkan karena kemampuan imunitas kelompok lansia menurun sesuai dengan peningkatan usia, sehingga produksi imunitas yang dihasilkan oleh tubuh lansia juga berkurang jumlahnya termasuk kecepatan respons imun melawan infeksi penyakit.teknik pengambila sampel yang 
baik adalah menggunakan air kumuran yang didapatkan secara langsung dari para lansia, sehingga akan mengdapatkan hasil yang lebih baik.(fatma, 2006)

Pada tabel 5 bahwa perilaku menyikat gigi menyikat gigi didapatkan hasil positif Candida sp sebanyak 31 sampel (91,18\%), sedangkan yang tidak menggunakan pasta gigi sebanyak 3 sampel $(8,82 \%)$. Hal ini di karenakan kebersihan mulut lansia yang tidak bersih, adanya penumpukan sisa zat makanan atau sisa-sisa makan yang mengandung gula, karna salah satu faktor yang mempercepat pertumbuhan Candida $s p$ adalah glukosa, sehingga didapatkan hasil positif Candida sp pada perilaku menyikat gigi dengan menggunakan pasta gigi.

\section{SIMPULAN}

Persentase Candida sp yang dibiakan pada media SDA (Saboraud Dextrose Agar) di Panti Sosial Tresna Werdha Budi Mulia 1 Cipayung Jakarta Timur adalah sebanyak 34 (54,9\%) sampel positif Candida sp. Hasil tertinggi kepadatan koloni yaitu pada (+) sebanyak 24 sampel (70,59\%), kepadatan koloni (++) yaitu sebanyak 4 sampel $(11,76 \%)$, serta kepadatan koloni $(+++)$ sebanyak 6 sampel $(17,65 \%)$

Jamur Candida sp lebih banyak ditemukan pada lansia dengan frekuensi menyikat gigi $>1 \mathrm{x}$ sehari sebanyak 24 sampel (70,59\%) dibandingkan dengan frekuensi menyikat gigi 1x sehari sebanyak 7 sampel $(20,59 \%)$ dan tidak menyikat gigi sebanyak 3 sampel (8,82\%). Pada perilaku mneyikat gigi menggunakan pasta gigi didapatkan hasil positif Candida sp sebanyak 31 sampel (91,18\%) dan 3 sampel (8,82\%) positif Candida sp tidak menggunakan pasta gigi.

Berdasarkan adanya keluhan berupa sariawan didapatkan hasil positif Candida sp sebanyak 6 sampel yaitu 17,65\% dan tidak ada keluhan sariawandengan hasil negatif Candida sp sebanyak 28 sampel yaitu $82,35 \%$.

\section{UCAPAN TERIMA KASIH}

Penulis mengucapkan terima kasih kepada Panti Sosial Tresna werdha Budi Mulia 1 Cipayung Jakarta Timur dan Prodi D III Analis Kesehatan Universitas MH Thamrin berperan serta dalam penelitian ini. 


\section{DAFTAR PUSTAKA}

1. Afrilia, Anis. 2012. Keberadaan Candida sp. Pada Rongga Mulut Mahasiswa STIKes MH Thamrin Pemakai Pesawat Orthodonti (Behel), Karya Tulis, Analis Kesehatan Universitas Mh Thamrin, Jakarta.

2. Akpan A, Morgan R. Oral Candidiasis. Postgard Med Journal. 2002; 78: 455 - 459.

3. Dian, 2013. Profil Spesies Candida pada pasien Candidiasis Rongga Mulut. KaryaTulis. Universitas Sumatera Utara.

4. Dwi, Asti. 2016. Pemeriksaan Candida albicans Pada Air Kumuran Penderita Diabetes MelitusvWilayah RT 003/001 Pinang Ranti Jakarta Timur. Karya Tulis Ilmiah. Universitas MH Thamrin.

5. Fakultas Kedokteran Universitas Indonesia. 1982. Candida Dan Kandidiasis Pada Manusia. Balai Penerbit FKUI, Jakarta.

6. Fatma. 2006. Respon Imunitas Yang Rendah PadaTubuh Manusia Usia Lanjut. Program Studi Kesehatan Masyarakat. Universitas Indonesia.

7. Gaib, Zulfikar. 2013. Faktor- faktor yang Berpengaruh Terhadap Terjadinya Kandidiasis Eritematosa Pada Pengguna Gigi Tiruan Lengkap, Karya Tulis. Universitas Sam Ratulangi.

8. Indriana, Y. 2004. Religiositas Orang Lanjut Usia ditinjau dari Tingkat Pendidikan Laporan Penelitian. Semarang: Program Studi Psikologi Fakultas Kedokteran Universitas Diponegoro.

9. Isro'in, L., Andarmoyo, S. 2012. Personal /hygiene Konseo, Proses dan Aplikasi dalam Praktik Keperawatan, Graha Ilmu Yogyakarta.

10. Jawetz M., Adelberg, Brooks GF, Butel JS, and Morse SA. 2008. Jawetz, Melnick \& Adelberg's Medical Microbiologi, $23^{\text {th }}$ ed. Jakarta: EGC. hal 658.

11. Jayanti, Zephyra. 2017. Faktor-fator Yang Mempengaruhi Keberadaan Candida albicans Pada Rongga Mulur Lansia Yang Menggunakan Gigi Tiruan Di Panti Sosial Tresna Werdha Budi Mulia 1 Cipayung Jakarta Timur, Karya Tulis. Universitas MH Thamrin.

12. Komariah. 2009. Karakteristik Candida sp di Rongga Mulut dan Hubunganya dengan Karies pada Murid SD 18 pagi. Karya Tulis, Fakultas Kedokteran Universitas Indonesia, Jakarta.

13. Kumar, Surinder. 2016. Essentials Of Microbiology. Jaypee Brothers Medical Publisher.

14. Mulyati, R. 2016. Buku Penuntun Praktikum Mikologi, Prodi Analis Kesehatan, Universitas MH Thamrin, Jakarta.

15. Notoatmodjo, S. 2010. Promosi Kesehatan dan Ilmu Perilaku. Rineka Cipta, Jakarta.

16. Prasetyo. 2012. Pemeriksaan Candida albicans Pada Usap Vagina Wanita Hamil Di Rumah Bersalin Kasih Ibu Tangerang. Karya Tulis. Analis Kesehatan Universitas MH Thamrin, Jakarta.

Open Journal System (OJS): journal.thamrin.ac.id

http://journal.thamrin.ac.id/index.php/anakes/issue/view/36 
17. Reed BD, Gorenflo DW, Gillespie B, dkk. 2000. Sexual Behaviours and Other Risk Factor For Candida vulvovaginitis. J Wome Health.

18. Ridhawati, S.Komariah. 2012. Kolonisasi Candida Pada Rongga Mulut. Jakarta. Universitas Indonesia.

19. Suprihatin S.D. 1982. Candida dan Kandidiasis Pada Manusia. Balai Penerbit Fakultas Kedokteran Universitas Indonesia, Jakarta.

20. Tortora, G.J, B.R., \& Case, C.L. 2004. Microbiology an Introduction. Eighth Edition, San Fransisco, Benjamin Cummings. 606-7.

21. Whidyaningrum, Sheina. 2002. Gambaran Oral Kandidiasis Pada Pengguna Gigi Tiruan Lepasan Berbasis Akrilik Di Yogyakarta. Fakultas Kedokteran Gigi. Universitas Muhamadiah Yogyakarta 